\title{
Evaluation of Body Weight, Serum Lipid Profile, Glucose Homeostasis, Oxidative Stress and Hepatic Function in Healthy Mice Fed With Zinc Sulphate Supplementation
}

\author{
Md. Atiqur Rahman ${ }^{1}$, Mohammad Tohidul Amin ${ }^{1}$, Sayema Arefin², Dipty Rani Bhowmik ${ }^{1}$, \\ Md. Abdur Rahman Ripon ${ }^{1}$ and Mohammad Salim Hossain ${ }^{1}$ \\ ${ }^{1}$ Department of pharmacy, Noakhali Science and Technology University, Sonapur, Noakhali 3814, Bangladesh \\ ${ }^{2}$ Department of Pharmacy, Mawlana Bhashani Science and Technology University, Tangail 1902, Bangladesh
}

(Received: August 26, 2020; Accepted: May 21, 2021; Published (web): June 20, 2021)

\begin{abstract}
The present research study was designed to evaluate the effect of zinc supplementation on body weight, serum triglyceride, cholesterol, glucose homeostasis, oxidative stress, and hepatic function in mice. Mice were treated with zinc sulphate at an equivalent weight of $6.5 \mathrm{mg} / \mathrm{kg}$-body weight elemental zinc for four weeks. Bodyweight, serum glucose, triglyceride, cholesterol, serum MDA, nitric oxide, vitamin C, and hepatic enzymes level were determined at the end of the study period. Data from this study showed that supplementation with zinc in mice maintained a balanced blood glucose homeostasis throughout the experimental period. Moreover, treatment with zinc showed a significant $(\mathrm{p}<0.05)$ decrease in serum triglyceride and cholesterol level along with a decrease in the body weight compared to control. Treatment with zinc significantly attenuated the rate of lipid peroxidation whereas increased the level of vitamin $\mathrm{C}$ and NO level. The protective effect of zinc on liver activity was observed. Treatment with zinc showed a strong negative association with serum total cholesterol $(r=-0.934, p=0.02)$, triglycerides level $(r=-0.709, p=0.05)$, and body weight $(r=-0.899, p=0.01)$. The present findings demonstrate that zinc supplementation can be helpful to maintain a glucose homeostasis, ameliorate hyperlipidemia, oxidative stress, and liver dysfunction. Therefore, zinc supplementation can be suggested to alleviate diseases associated with metabolic syndrome and oxidative stress.
\end{abstract}

Key words: Zinc, Lipid Profile, Metabolic disease, Oxidative stress, Liver function.

\section{INTRODUCTION}

Zinc being a member of essential micro-mineral, plays a major role in different physiological and biochemical events including regulation of gene expression, hormone synthesis, storage, and actions, maintaining structural integrity of chromatin and biological membrane. ${ }^{1}$ The amount of zinc required for the maintenance of the body is quite small but its effect on various enzymatic and physiological mechanisms cannot be overlooked. ${ }^{2}$ Alteration in the metabolic and oxidative markers in the body can lead to pathological progression of a diverse range of disease processes. Despite the role of zinc trace mineral on various metabolic disorders and oxidative

Correspondence to: Mohammad Salim Hossain

Tel.:+ 88001711200410

Email: pharmasalim@yahoo.com; pharmasalim@nstu.edu.bd

Dhaka Univ. J. Pharm. Sci. 20(1): 59-66, 2021 (June)

DOI: https://doi.org/10.3329/dujps.v20i1.54033 stress-mediated diseases is still inconclusive. Shen et $a .^{3}$ reported that deficiency of zinc affects the pathway of lipid metabolism and causes an increase in the serum lipid profile, total cholesterol, and triglycerides. Hyperlipidemic patients have a significantly lower level of serum zinc in comparison to healthy individuals. ${ }^{4}$ Several studies suggest that supplementation of zinc has positive effects on serum lipid profiles and it significantly reduces cholesterol and triglycerides. ${ }^{5,6}$ Nevertheless, several studies also did not agree with these results. ${ }^{7,8}$ The deficiency of zinc is also associated with insulin resistance, glucose tolerance, and obesity. ${ }^{9}$ Studies suggest that zinc supplementation may be beneficial in treating diabetes ${ }^{10}$ a condition associated with elevated blood glucose level, and are involved in the synthesis, release, and action of insulin. ${ }^{11}$ In addition, there is a lower blood level of vitamins and minerals in 
overweight and obese individuals compared to nonoverweight and non-obese individuals. ${ }^{12}$ Therefore, supplementation of zinc may benefit obese and overweight individuals. The deficiency of zinc in the body increases oxidative stress which consequently causes oxidative damage to the proteins, lipids, and DNA. ${ }^{13}$ Experimental observation revealed that treatment with zinc can attenuate oxidative stress by decreasing lipid peroxidation. ${ }^{14,15}$ Besides, deficiency of vitamin $\mathrm{C}$, a non-enzymatic antioxidant, leads to an increase in oxidative stress. ${ }^{16}$ However, there is no data available relating to the effect of zinc on vitamin $\mathrm{C}$ in the body. Moreover, nitric oxide (NO) level is also decreased as a result of zinc deficiency. ${ }^{17}$ It is reported that zinc administration can increase the NO level in the body ${ }^{18}$ Interestingly, in 2008, Zhu et al. ${ }^{19}$ proposed that optimum $\mathrm{NO}$ level can act as an antioxidant but elevated NO level may promote the formation of reactive oxygen species (ROS). The role of zinc in NO levels associated redox system is still ambiguous. However, elevated oxidative stress in the body acts as a crucial factor in the structural and functional abnormalities of the liver. ${ }^{20}$ It is noted that zinc supplementation improves the outcome of diseases linked to liver failure. ${ }^{21}$ The human body is exposed to elemental zinc from a variety of sources including medicines and food supplements. In this current study, we aimed to gain more insight knowledge about the role of zinc supplementation in maintaining lipid profile, blood glucose, body weight, oxidative stress, and liver function in healthy mice.

\section{MATERIALS AND METHODS}

Materials. The test material that was selected for the present research study was zinc sulphate heptahydrate, $\mathrm{ZnSO}_{4} .7 \mathrm{H}_{2} \mathrm{O}$ (Merck, India). An amount of $28.76 \mathrm{mg} / \mathrm{kg}$ bodyweight $\mathrm{ZnSO}_{4} .7 \mathrm{H}_{2} \mathrm{O}$ equivalent to $6.5 \mathrm{mg} / \mathrm{kg}$ bodyweight elemental $\mathrm{Zn}$ was administered to each mouse on daily basis for 28 days.

Methods. Experimental design. Twenty Swiss albino mice (sex: male, age of two to three months) were recruited from the animal house of the Department of Pharmacy, Jahangirnagar University,
Dhaka, Bangladesh, and were allowed to acclimatize for two weeks before the commencement of the experiment. Animals were divided into two groups, each having 10 mice and indicated as a control group and zinc supplement group. Both groups of mice having an average weight of $26 \mathrm{gm}$ were selected for the experiment. The animals were housed under standard laboratory and pathogen-free conditions: relative humidity $55-65 \%$, temperature $24.0 \pm 2.0^{\circ} \mathrm{C}$, $12 \mathrm{~h}$ light, and $12 \mathrm{hr}$ dark cycle. Husk and excreta were removed from the cages regularly to maintain a healthy environment. Each mouse of the zinc supplement group was supplemented with $6.5 \mathrm{mg} / \mathrm{kg}$ elemental zinc orally daily along with normal feed while the control group was given only normal feed. A fixed amount of dietary feed was provided daily to both groups and weight changes of the mice were monitored throughout the experimental period. After the treatment period, the animals were anesthetized and blood samples were collected through the cardiac puncture into labeled tubes. The blood was centrifuged at $3000 \mathrm{rpm}$ for $10 \mathrm{~min}$ to separate serum for biochemical analyses.

Estimation of biomarkers. Serum total cholesterol $^{22}$ and triglyceride ${ }^{23}$ were determined by enzymatic method using a commercially available assay kit (Linear Chemicals S.L., Barcelona, Spain). The fasting glucose levels of all the animals were estimated weekly by using the glucose oxidase method. ${ }^{24}$ Lipid peroxidation rate was assessed by measuring serum malondialdehyde (MDA) level according to the modified method illustrated by Buege and Aust. $^{25}$ The phenyl-hydrazine spectrophotometry method was followed for the estimation of the concentration of vitamin $\mathrm{C}$ in the serum. ${ }^{26} \mathrm{NO}$ concentration was determined using an indirect method based on the measurement of nitrate concentration in serum according to Griess's reaction. ${ }^{27}$ Serum liver enzymes, alanine aminotransferase (ALT), and aspartate aminotransferase (AST), the level was estimated using a commercially available assay kit (Randox Laboratories Limited, United Kingdom) according to the manufacturer's instruction applied in our previous study. ${ }^{28}$ 
Statistical analysis. All data are presented as mean \pm SEM. The unpaired t-test was used to determine statistical differences between the control and experimental group. Statistical analyses were considered to be significant at $* p<0.05$. All statistical analysis was performed using SPSS Statistics 20 (IBM Corp.).

\section{RESULTS AND DISCUSSION}

Effect on body weight. The effect of zinc supplementation on body weight is summarized in Table 1. The initial weight of the control and zinc supplemented group of mice was $26.18 \pm 0.36 \mathrm{gm}$ and $26.18 \pm 0.40 \mathrm{gm}$, respectively. After four weeks of treatment, the zinc supplemented group had a comparatively lower body weight $(30.64 \pm 0.36 \mathrm{gm})$ $(* * \mathrm{p}<0.01)$ than the control group $(31.48 \pm 0.40$ gm). Zinc supplement group increased in weight $17.03 \%$ whereas $20.24 \%$ body weight was increased in the control group from the initial to the experimental period.

Table 1. Effect of Zinc Supplementation on body weight of mice.

\begin{tabular}{lcc}
\hline Test parameter & Control & Zinc supplement \\
\hline Initial body weight $(\mathrm{gm})$ & $26.18 \pm 0.40$ & $25.87 \pm 0.36$ \\
$\%$ body weight increased & $20.24 \pm 0.12$ & $17.03 \pm 63^{*}$ \\
(after 4 week) & & \\
\hline
\end{tabular}

Values are presented as mean \pm SEM, $* \mathrm{p}<0.05$ versus Control.

Effect on lipid profile. After 4 weeks of the experiment, zinc supplementation showed a significant effect on the serum lipid profile, total cholesterol, and triglycerides. The effect of zinc supplementation on blood lipid profile is presented in Table 2. The zinc supplemented group shows a significant decrease in total cholesterol level (117.71 $\pm 8.64 \mathrm{mg} / \mathrm{dl})(* \mathrm{p}<0.05)$ compared to control group $(217.1426 \pm 48.03 \mathrm{mg} / \mathrm{dl})$. Treatment with zinc resulted in a decrease in the triglycerides level $(117.71 \pm 8.64 \mathrm{mg} / \mathrm{dl})\left({ }^{*} \mathrm{p}=0.02963\right)$ in comparison to the control group $(217.1426 \pm 48.03 \mathrm{mg} / \mathrm{dl})$.
Table 2. Effect of zinc supplementation on serum biochemical parameters in mice.

\begin{tabular}{lcc}
\hline Test parameter & Control & $\begin{array}{c}\text { Zinc } \\
\text { supplement }\end{array}$ \\
\hline $\begin{array}{l}\text { Serum Total Cholesterol } \\
(\mathrm{mg} / \mathrm{dl})\end{array}$ & $217.14 \pm 48.03$ & $117.71 \pm 8.64^{*}$ \\
$\begin{array}{l}\text { Serum Triglyceride } \\
(\mathrm{mg} / \mathrm{dl})\end{array}$ & $591.43 \pm 144.16$ & $191.43 \pm 53.99^{*}$ \\
$\begin{array}{l}\text { Serum MDA } \\
(\mathrm{nmol} / \mathrm{ml})\end{array}$ & $2.73 \pm 0.43$ & $1.71 \pm 0.18^{*}$ \\
$\begin{array}{l}\text { Serum Vitamin C } \\
(\mathrm{mg} / \mathrm{dl})\end{array}$ & $1.53 \pm 0.01$ & $2.25 \pm 0.25^{*}$ \\
$\begin{array}{l}\text { Serum NO } \\
(\mu \mathrm{M} / \mathrm{ml})\end{array}$ & $9.32 \pm 0.14$ & $10.54 \pm 0.37^{*}$ \\
\hline
\end{tabular}

Values are presented as mean \pm SEM, $* p<0.05$ versus Control.

Effect on glucose homeostasis. During the experimental period, the fasting blood glucose levels of both groups of mice were measured on the $7^{\text {th }}$, $14^{\text {th }}, 21^{\text {th }}$ and $28^{\text {th }}$ day. The initial average fasting blood glucose level of the control group was 3.78 $\mathrm{mmol} / \mathrm{L}$ and the fasting blood glucose level for the consecutive three weeks were $6.16 \mathrm{mmol} / \mathrm{l}, 5.34$ $\mathrm{mmol} / \mathrm{l}, 3.26 \mathrm{mmol} / \mathrm{l}$ and $5.2 \mathrm{mmol} / \mathrm{l}$. But the initial mean fasting blood glucose levels of the zinc supplement group of mice was $5.0 \mathrm{mmol} / \mathrm{l}$ and fasting mean blood glucose level of the consecutive 3 weeks were $5.34 \mathrm{mmol} / \mathrm{l}, 5.26 \mathrm{mmol} / \mathrm{l}, 4.56 \mathrm{mmol} / \mathrm{l}$ and, $5.50 \mathrm{mmol} / \mathrm{l}$ (Figure 1).

Effect on oxidative stress. We estimated the level of serum MDA concentrations, which is a convenient biomarker of lipid peroxidation, to determine the effect of zinc on oxidative stress. Zinc supplement administration significantly attenuated serum MDA concentrations compared to the control group $(* \mathrm{p}<0.05)$ (Table 2$)$.

Effect on vitamin $\mathbf{C}$ content. The effect of zinc on vitamin $\mathrm{C}$ levels is depicted in table 2 . There was a significant improvement of the serum levels of the antioxidant vitamin $\mathrm{C}$ in the zinc supplement group compared with the control group of animals $(* \mathrm{p}<$ 0.05).

Effect on NO activity. Treatment with zinc significantly ameliorated the NO level in the zinc supplement group as compared with the control group $(* * \mathrm{p}<0.01)($ Table 2$)$. 
Effect on liver function. As shown in figure 2, the administration of zinc significantly decreased the serum liver enzymes, ALT $(* p<0.05)$, and AST $(* p$
$<0.05$ ), concentration of the experimental zinc supplement group when compared with control.

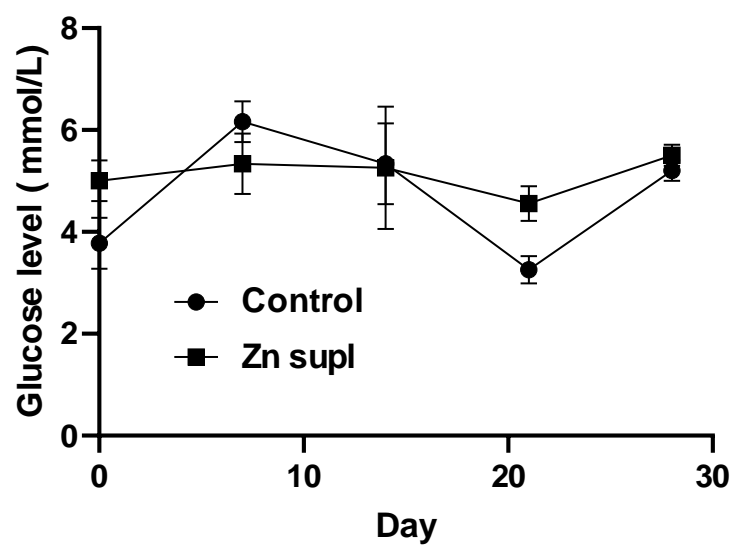

Figure 1. Effect of Zinc sulphate on glucose homeostasis in mice model.

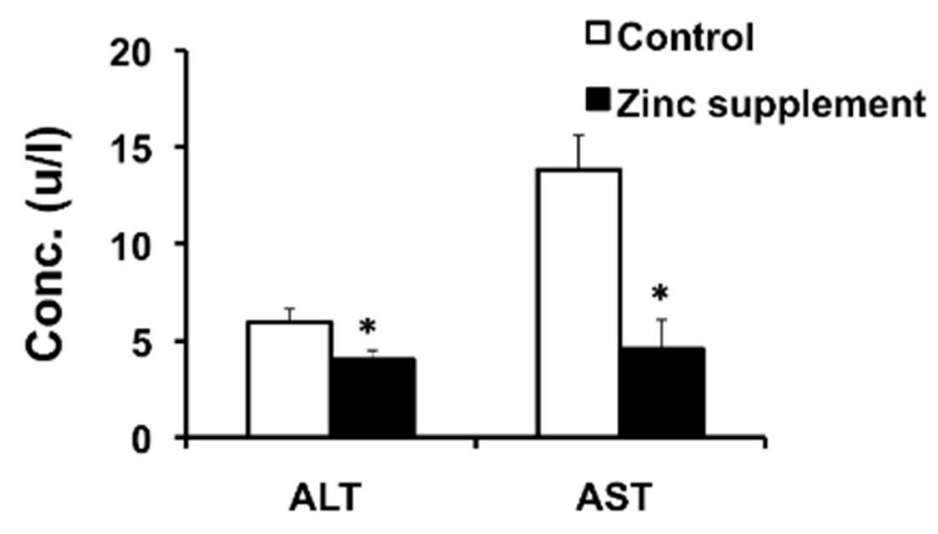

Figure 2. Effect of $\mathrm{Zn}$ supplementation on liver enzyme of mice. ${ }^{*} p<0.05$ versus control

Metabolic syndrome includes a group of conditions characterized by an imbalance in blood sugar and abnormal body weight, cholesterol, or triglyceride levels that ensue together, increasing the risk of heart disease, stroke, and diabetes. The present research study shows that zinc trace minerals have a significant effect on serum lipid profile, blood glucose level, and body weight. In the present study, $\mathrm{ZnSO}_{4}$ was used as a source of elemental zinc. In all the Asian countries, serum lipid profile level is increasing day by day with an increase in cardiovascular disease. ${ }^{29}$ The changes in lipid profile may vary depending on the types of food intake and physical activity. The body needs a certain amount of cholesterol and triglycerides to work properly. But too much cholesterol and triglycerides in the blood are a risk factor for heart disease, fatty liver disease, etc. $^{30}$ The present research study indicates that treatment with zinc significantly decreases the body weight with the decrease in both the total cholesterol and triglycerides level (Tables 1 and 2). Moreover, treatment with zinc showed a strong negative association with serum total cholesterol $(r=-0.934, p$ $=0.02)$, triglycerides level $(r=-0.709, p=0.05)$, and body weight $(r=-0.899, \mathrm{p}=0.01)$. Similar to our studies, several studies also found that 
supplementation of zinc has decreasing effects of serum lipid profiles and may be beneficial to reduce atherosclerosis-related morbidity and mortality., Blood glucose level serves as an important factor in energy homeostasis in the body. Glucose levels above or below the normal range are indicative of the presence of disease states. Islam et al. ${ }^{31}$ found that diabetic patients, having an elevated glucose level, usually have significantly lower serum zinc concentration than healthy individuals. Confield et $a l .{ }^{32}$ investigated that type II diabetes mellitus patients suffered from greater zinc excretion when compared to controls, and it was significantly correlated with urinary glucose. Roussel et al. ${ }^{33}$ observed that supplementation of zinc could improve glucose tolerance and insulin sensitivity in type 2 diabetes mellitus through its antioxidant effects. Surprisingly, in our study, in the control group of mice, there were a fluctuation in the mean fasting blood glucose level from the initial up to the consecutive three weeks whereas the zinc supplement group showed a balanced mean fasting blood glucose level throughout the experimental period (figure 1). A positive correlation $(r=0.920)$ was also observed between zinc supplementation and glucose level. So, it is clear that zinc may play a pivotal role in the glucose homeostasis of the body. Similarly, Gunasekara et al..$^{34}$ speculated that the improvement of glycemic control was mainly initiated by a beneficial effect of zinc as an antioxidant on $\beta$ cells. Similar to our studies, Chausmer AB. ${ }^{35}$ also reported that supplementation of zinc together with controlling dietary regimen might be useful to maintain blood glucose level and to regulate insulin secretion. Although a fixed amount of dietary food was given daily to both groups, supplementation of zinc showed a balanced bodyweight improvement and their percentage of improvement in weight was less compared to the control group of animals during the experimental period. During the continuous observations, the zinc supplement group seemed a loss in appetite as they were spending much time in completing their foods in comparison to control. Similar results were observed by some of the previous studies that examined the effect of zinc supplementation on body weight. ${ }^{36}$ Although we did not study possible mechanism to address the effect of zinc on body weight maintenance directly, but we are postulating that 1) zinc might be involved in controlling appetite through the manipulation of ghrelin and leptin system, 2) the role of zinc on the reduction of a serum lipid profile that ultimately will reduce the incidence of overweight. 3) effect of zinc on glucose homeostasis and maintaining insulin action and glucagon release.

Besides, in the present study, the effect on the antioxidant-oxidant balance due to the intake of zinc was also assessed. In various disease conditions such as in diabetes, cancer, atherosclerosis, etc., oxidative stress in the body is increased due to either elevated production of oxygen-nitrogen derived free radical species or for reduced capacity of the antioxidant defense. Ultimately, cellular components especially lipids are being attacked by these free radicals and cause damage, by a complicated process termed as lipid peroxidation. ${ }^{37}$ Several studies stated that elevation of oxidative stress and damage to the proteins, lipids, and DNA is facilitated by a deficiency of zinc trace mineral in the body, which consequently may lead to various complex intracellular diseases. ${ }^{13}$ In the present study, the administration of zinc to mice significantly diminished the free radical formation and caused attenuation of oxidative stress as indicated by a decrease in serum lipid peroxidation product, the MDA levels. Similar to our study, several studies also documented the ameliorative effect of zinc on oxidative stress in the body. ${ }^{5,6}$ Vitamin $\mathrm{C}$ acts as an important non-enzymatic antioxidant in the body as it decreases the adverse effect of reactive species such as oxidative damage to macromolecules including lipids, DNA, and proteins. ${ }^{38}$ Experimental observations revealed that both zinc and vitamin $\mathrm{C}$ deficiency leads to an increase in the oxidative stress, that's why we speculated the possibility of having a strong relationship between vitamin $\mathrm{C}$ and zinc in the body. Our study demonstrates that treatment with zinc can be beneficial to ameliorate the level of vitamin $\mathrm{C}$ in the body and improvement of this vitamin will aid to promote the immune system and 
helps fight off infections. ${ }^{39}$ There is no previous research available relating the effect of zinc on vitamin $\mathrm{C}$ levels in the body. We also investigated the effect of zinc on the activity of NO in mice. In low concentrations, NO plays an important antioxidant role in regulating various physiological functions, but in high concentration, it may contribute to the progression of various disease processes by the elevation of reactive species such as in chronic renal disease, vascular disease, hypothyroidism, etc. ${ }^{40}$ So, the maintenance of proper activity of NO is crucial for its key physiological and biochemical functions. When the findings obtained at the end of the present experiment are investigated with particular regard to NO, it is observed that total nitrite levels are slightly increased in the serum of mice after treatment with zinc when compared to the control group. Similar to our study, Atakisi et l. $^{24}$ observed that treatment with zinc on quills raised the NO level in the body. Muhammad et $a l^{41}$ also showed that the administration of zinc improved endothelial function by increasing the NO level when compared with hypertensive control rats. In our study, zinc is decreasing the oxidative stress by attenuating lipid peroxidation and increasing the non-enzymatic antioxidant. So, treatment with an adequate amount of zinc will ameliorate the NO activity by preceding its oxidation and maintaining the optimum levels, which will impart a partial favorable function as an antioxidant. ${ }^{42}$

In addition, zinc deficiency is connected to a diverse range of disease conditions associated with liver damage including viral hepatitis, chronic liver disease, liver cirrhosis, and hepatocellular carcinoma. ${ }^{43}$ Liver or hepatic damage is connected to excessive production of ROS and the presence of oxidative stress within hepatocytes. ${ }^{26}$ The hepatocyte membrane distortion is associated with membrane leakage of the hepatocyte cytosolic contents which is manifested by the elevation of serum liver enzymes namely ALT and AST, as a marker of hepatocellular damage. That's why estimating the activities of the serum marker enzymes can be a useful quantitative biomarker of the liver function. Therefore, the observed significant decrease in serum ALT and AST when compared with control for the groups treated with zinc suggest the hepatoprotective role of zinc which can be due to the effect of zinc on the attenuation of oxidative stress. These findings are similar to the findings of other researchers. ${ }^{21,23}$ These observations corroborate the hepatoprotective role of zinc and this mineral exhibits the antioxidant effect by attenuating the oxidative stress and ameliorating the antioxidant defense. However, whether the improvement of vitamin $\mathrm{C}$ and $\mathrm{NO}$ level in our study due to the intake of zinc is directly or indirectly linked to the hepatic protection needs further investigation.

\section{CONCLUSION}

The results of the present study entail that zinc, as an exclusively important nutrient of the body, plays a pivotal role in the regulation of various metabolic markers and antioxidant-oxidant status of the body. Therefore, zinc supplementation can be a potential medication for diseases associated with metabolic syndrome, oxidative stress, and inflammation.

\section{COMPETING INTEREST}

The authors declare that they have no competing interests.

\section{REFERENCES}

1. Meunier, N., O'connor, J. M., Maiani, G., Cashman, K. D., Secker, D. L., Ferry, M., Roussel, A. M., and Coudray, C. 2005. Importance of zinc in the elderly: the ZENITH study. Eur. J. Clin. Nutr. 59, S1-S4. Doi: 10.1038/sj.ejcn.1602286

2. Roohani, N., Hurrell, R., Kelishadi, R., and Schulin, R. 2013. Zinc and its importance for human health: An integrative review. J. Res. Med. Sci. 18, 144-157.

3. Shen, H., MacDonald, R., Bruemmer, D., Stromberg, A., Daugherty, A., Li, X., Toborek, M., and Hennig, B. 2007. Zinc deficiency alters lipid metabolism in LDL receptordeficient mice treated with rosiglitazone. J. Nutr. 137, 23392345 .

4. Al-Sabaawy, O. M. 2012. The relationship between serum lipid profile and selected trace elements for adult men in Mosul City. Oman Med. J. 27, 300-303.

5. Ranasinghe, P., Wathurapatha, W. S., Ishara, M. H, Jayawardana, R., Galappatthy, P., Katulanda, P., and Constantine, G. R. 2015. Effects of zinc supplementation on serum lipids: a systematic review and meta-analysis. Nutr. Metab. 12, 26. 
6. Afkhami-Ardekani, M., Karimi, M., Mohammadi, S. M., and Nourani, F. 2008. Effect of zinc sulfate supplementation on lipid and glucose in type 2 diabetic patients. Pak. J. Nutr.7, 550-553.

7. Kim, J., and Lee, S. 2012. Effect of zinc supplementation on insulin resistance and metabolic risk factors in obese Korean women. Nutr. Rres. Pract. 6, 221-25.

8. Roozbeh, J., Hedayati, P., Sagheb, M. M., Sharifian, M., Jahromi, A. H., Shaabani, S., Jalaeian, S., Raeisjalali, G. A., and Behzadi, S. 2009. Effect of zinc supplementation on triglyceride, cholesterol, LDL, and HDL levels in zincdeficient hemodialysis patients. Ren. Fail. 31, 798-801.

9. Tallman, D. L., and Taylor, C. G. 2003. Effects of dietary fat and zinc on adiposity, serum leptin and adipose fatty acid composition in c57bl/6j mice. J. Nutr. Biochem. 14, 17-23.

10. Jayawardena, R., Ranasinghe, P., Galappatthy, P., Malkanthi, R. L. D. K, Constantine, G. R., and Katulanda, P. 2012. Effects of zinc supplementation on diabetes mellitus: a systematic review and meta-analysis. Diabetol. Metab. Syndr. 4, 13.

11. Simon, S. F., and Taylor, C. G. 2001. Dietary zinc supplementation attenuates hyperglycemia in $\mathrm{db} / \mathrm{db}$ mice. Exp. Biol. Med. (Maywood). 226, 43-51.

12. Garcia, O. P., Long, K. Z., and Rosado, J. L. 2009. Impact of micronutrient deficiencies on obesity. Nutr. Rev. 67, 559572.

13. Ho, E. 2004. Zinc deficiency, DNA damage and cancer risk. J. Nutr. Biochem. 15, 572-578.

14. Bao, B., Prasad, A. S., Beck, F. W., Fitzgerald, J. T., Snell, D., Bao, G. W., Singh, T., and Cardozo, L. J. 2010. Zinc decreases C-reactive protein, lipid peroxidation, and inflammatory cytokines in elderly subjects: a potential implication of zinc as an atheroprotective agent. Am. J. Clin. Nutr. 91, 1634- 1641. Doi: 10.3945/ajen.2009.28836.

15. Bicer, M., Gunay, M., Baltaci, A. K., Uney, K., Mogulkoc, R., and Akil, M. 2012. Effect of zinc supplementation on lipid peroxidation and lactate levels in rats with diabetes induced by streptozotocin and subjected to acute swimming exercise. Bratisl. Med. J. 113, 199-205.

16. Dalvi, S. M., Patil, V. W., Ramraje, N. N., Phadtare, J. M., and Gujarathi, S. U. 2012. Nitric oxide, carbonyl protein, lipid peroxidation and correlation between antioxidant vitamins in different categories of pulmonary and extra pulmonary tuberculosis. Malay. J. Med. Sci. 20, 21- 30.

17. Baltacia, A. K., Mogulkoca, R., Turkozb, Y., Bedizc, C. S., and Ozugurlub, F. 2004. The effect of pinealectomy and zinc deficiency on nitric oxide levels in rats with induced Toxoplasma gondii infection. Swiss Med. Wkly. 134, 359363.

18. Atakisi, O., Atakisi, E., and Kart, A. 2009. Effects of dietary zinc and 1-arginine supplementation on total antioxidants capacity, lipid peroxidation, nitric oxide, egg weight, and blood biochemical values in Japanase Quails. Biol. Trace Elem. Res. 132, 136-143. Doi: 10.1007/s12011-009-8378-x.
19. Zhu, S., Sun, L., Liu, M., and Zhou, J. 2008. Effect of nitric oxide on reactive oxygen species and antioxidant enzymes in kiwifruit during storage. J. Sci. Food Agr. 88, 2324-2331. Doi:10.1002/jsfa.3353

20. Cichoż-lach, H., and Michalak, A. 2014. Oxidative stress as a crucial factor in liver diseases. World J. Gastroenterol. 20, 8082-8091. doi: 10.3748/wjg.v20.i25.8082

21. Matsuoka, S., Matsumura, H., Nakamura, H., Oshiro, S., Arakawa, Y., Hayashi, J., Sekine, N., Nirei, K., Yamagami, H., Ogawa. M., Nakajima, N., Amaki, S., Tanaka, N., and Moriyama, M. 2009. Zinc supplementation improves the outcome of chronic hepatitis C and liver cirrhosis. J. Clin. Biochem. Nutr. 45, 292-303.

22. Allain, C. C., Poon, L. S., and Chan, C. S. G. 1974. Enzymatic determination of total serum cholesterol. Clinical Chem. 20, 470-475.

23. Tietz, N. W. 1990. Clinical Guide to Laboratory Tests. W.B. Saunders, Philadelphia, Pa, USA, 2nd edition, pp. 554-556.

24. Trinder, P. 1969. Determination of blood glucose in blood using glucose oxidase with an alternative oxygen acceptor. Ann. Clin. Biochem. 6, 24-25.

25. Buege, J. A., and Aust, S. D. 1978. Microsomal lipid peroxidation. Methods Enzymol. 52, 302-310.

26. Lowry, H., Jeanne, A., and Lopez, O. A. 1945. The determination of ascorbic acid in small amounts of blood serum. J. Bio.l Chem. 162, 609-615.

27. Griess, P. 1879. Bemerkungen zu der abhandlung der H.H. Weselsky und Benedikt "Ueber einige azoverbindungen." Chem. Ber.12, 426-428.

28. Uddin, M. G., Hossain, M. S., Rahman, M. A., Uddin, A. H. M.M., Bhuiyan, M. S. 2017. Elemental zinc is inversely associated with C- reactive protein and oxidative stress in chronic liver disease. Bio. Trace Elem Res. 178, 189-193.

29. Khoo, K. L., Tan, H., Liew, Y. M., Deslypere, J. P., and Janus, E. 2003. Lipids and coronary heart disease in Asia. Atherosclerosis. 169, 1-10.

30. Ma, H. 2006. Cholesterol and Human Health. J. Am. Sci. 2, 46-50.

31. Islam, M. R., Arslan, I., Attia, J., McEvoy, M., McElduff, P, and Basher, A. 2013. Is serum zinc level associated with prediabetes and diabetes?: A cross-sectional study from Bangladesh. PLoS ONE. 8, e61776.

32. Confield, W. K., Handbidge, I. N., and Jahnson, L. K. 1984. Zinc nutrition in type I diabetes mellitus: relationship to growth measures and metabolic control. J. Pediatr. Gastroenterol. Nutr. 3, 577-584.

33. Roussel, A. M., Kerkeni, A., Zouari, N., Mahjoub, S., Matheau, J. M., and Anderson, R. A. 2003. Antioxidant effects of zinc supplementation in Tunisians with type 2 diabetes mellitus. J. Am. Coll. Nutr. 22, 316-321.

34. Gunasekara, P., Hettiarachchi, M., Liyanage, C., and Lekamwasam, S. 2011. Effects of zinc and multimineral vitamin supplementation on glycemic and lipid control in adult diabetes. Diabetes Metab. Syndr. Obes. 4, 53-60.

35. Chausmer, A. B. 1998. Zinc, insulin and diabetes. J. Am. Coll. Nutr. 17, 109-1015. 
36. Payahoo, L., Ostadrahimi, A., Mobasseri, M., Bishak, Y. K., Farrin, N., Jafarabadi, M. A., and Mahluji, S. 2013. Effects of zinc supplementation on the anthropometric measurements, lipid profiles and fasting blood glucose in the healthy obese adults. Ad. Pharm. Bull. 3, 161-165.

37. Ayala, A., Muñoz, M. F., and Argüelles, S. 2014. Lipid peroxidation: production, metabolism, and signaling mechanisms of malondialdehyde and 4-hydroxy-2-nonenal. Oxi. Med. Cell. Longev. Article ID 360438. Doi: http://doi.org/10.1155/2014/360438

38. Naidu, K. A. 2003.Vitamin C in human health and disease is still a mystery? An overview. Nutr. J. 2, 7. Doi: 10.1186/1475-2891-2-7

39. Padayatty, S. J., Wang, Y., Kwon, O., Lee, J. H, Chen, S., Corpe, C., Dutta, A., Dutta, S. K., and Levine, M. 2003. Vitamin $\mathrm{C}$ as an antioxidant: evaluation of its role in disease prevention. J. Am. Coll. Nutr. 22, 18-35.
40. Antosova, M., Plevkova, J., Strapkova, A., and Buday, T. 2012. Nitric oxide-important messenger in human body. Open J. Mol. Integr. Physiol. 2, 3. Doi: 10.4236/ojmip.2012.23014

41. Muhammad, S. A., Bilbis, L. S., Saidu, Y., and Adamu, Y. 2012. Effect of antioxidant mineral elements supplementation in the treatment of hypertension in Albino Rats. Oxi. Med. Cell Longev. Article ID 134723. Doi: 10.1155/2012/134723

42. Wallace, J. L. 2005. Nitric oxide as a regulator of inflammatory processes. Mem. Inst. Oswaldo Cruz. 100, S1, 5-9.

43. Ebara, M., Fukuda, H., Hatano, R., Yoshikawa, M., Sugiura, N., Saisho, H., Kondo, F., and Yukawa, M. 2003. Metal contents in the liver of patients with chronic liver disease caused by hepatitis C virus. Reference to hepatocellular carcinoma. Oncology. 65, 323-330. 